\title{
A unified decision support tool for product management
}

\author{
H. E. Cook \\ C. J. Gauthier Professor \\ Department of Mechanical and Industrial Engineering \\ University of Illinois, Urbana, Illinois 61801 \\ Telephone: 217-244-799; Fax: 217-333-0721 \\ E-mail:cook@uxl.cso.uiuc.edu
}

\begin{abstract}
An integrated structured methodology is described for aiding product management decisions across all elements of the enterprise. Decisions on new product alternatives are based upon demand and profit forecasts determined from forecasts of the value of the proposed new product to the customer, manufacturing costs, investment levels, and forecasted actions of competitors. The model used to support the structured methodology is designed to be as simple as possible to treat the problem but having sufficient rigor to support trustworthy decision making. The major issues related to marketing, finance, design, engineering, manufacturing, service, environment, and quality management are encompassed by the methodology.
\end{abstract}

\section{Keywords}

New products, customers, profit, strategic goals, product realisation, structured methodologies, Total Quality Management, Quality Function Deployment, Taguchi Methods, decision support tool, value benchmarking 


\section{INTRODUCTION}

\subsection{Solving unstructured problems}

Product decisions are complex because the basic problem is unstructured due to the fact that there are many different ways to design, manufacture and market most products. Moreover, outcomes in the marketplace are not just a function of what you do to your product but also highly dependent on what your competitors do to theirs. Because of the complexity and uncertainty, tools are needed to bring order to the product realisation process and to manage its innate uncertainty so that good and timely decisions are the norm and not the exception.

Such tools are known as structured methodologies, one of the best known being Total Quality Management (TQM) (Gitlow, Oppenheim, and Oppenheim, 1995). Other well-known examples are Quality Function Deployment (QFD) (Akao, 1990; American Supplier Institute, 1993), Manufacturing Resource Planning (MRP) (Chase and Aquilano, 1995), Design of Experiments (DoE) (DeVor, Chang, and Sutherland, 1992), and just-in-time (JIT) (Schonberger, 1987) which deal with subsets of the general problem of product management.

\subsubsection{Need for continuous improvement}

Products must be continuously improved to survive in highly competitive markets. This in turn requires that continuous advances be made in the methods used by the enterprise in support of the product realisation process. Although the techniques in use today are much improved over those in place in the early 1980's, significant shortcomings remain. TQM, for example, now strongly supports such sound practices as statistical process control and design of experiments but many elements of TQM's unifying structure today are platitudes. The QFD discipline has caused enterprises to get closer to the customer and thereby gain a better understanding of customer needs before embarking on a new product. However, once the customer needs have been identified, the QFD deployment process rests on subjective judgements and fails to utilise more rigorous concepts from economic theory and statistics. Although Taguchi Methods (Taguchi and $\mathrm{Wu}$, 1980) have been shown to be very effective at the component level of design, a system level support tool akin to Taguchi Methods has not received wide usage. Finally, none of these tools are well integrated into an overall guiding structure which all of the stakeholders within the enterprise can embrace.

\subsubsection{Purpose}

The purpose of this paper is to first outline the key elements that a structured methodology for product management should have and then to review a structured methodology which contains those elements based upon a simple model of the marketplace collectively referred to as the S-Model (Cook and DeVor, 1991; Cook, 1992; Cook and Kolli, 1994; Kolli and Cook, 1994). 


\section{TIME-INVARIANT CUSTOMER NEEDS LOOP}

Structured methodologies for product management need to be developed around those elements of the product realisation process that are deemed as fundamental. The loop shown in Figure 1 which begins with customer needs is taken as being fundamental because it is time-invariant. Customers will always purchase products to fill their needs. Although a multitude of attributes are specified by the designer and manufactured into the product, only a select few -- the system level attributes - will be of direct importance to the customer. For example, a potential customer for a new vehicle does not care about the myriad details of the parts that form the braking subsystem, only that the vehicle stops reliably, smoothly, quietly, and in a short distance.

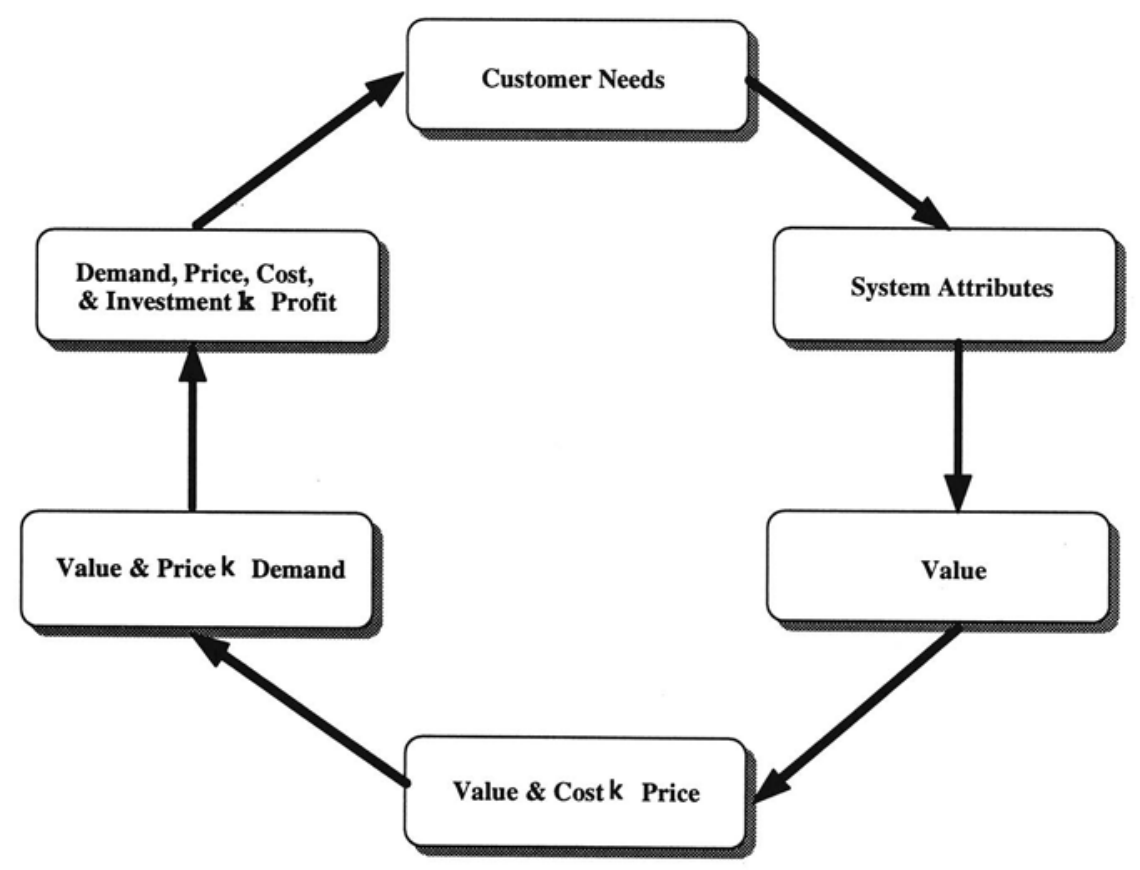

Figure 1: The time-invariant customer needs loop. 
If a buyer found that an unexpected squeal was always emitted during braking, this would result in dissatisfaction and a loss of value. If the brake squeal intensity at every application was at $120 \mathrm{~dB}$, the threshold of pain, the loss of vehicle value might be $100 \%$ in that the buyer would not drive the vehicle until it was fixed. The problem might have resulted from the brake pad chemistry being out of specification, a component level attribute, but what affected the customer was the system level attribute, noise. Thus as we move around the loop in Figure 1, we see that customer needs are translated into product value through the system level attributes.

Product value and cost place upper and lower bounds on price. If price is higher than value no one will purchase the product and, if price is lower than cost, money will be lost on every sale. Value and price drive demand. Profit, which is determined by demand, price, cost, and investment, creates the working capital needed by the enterprise to develop new products to meet the growing expectations of its customers.

A major challenge in managing products through the customer needs loop is to reliably connect system attributes to product value and to quantify how the demand of a product is affected by changes in its price and value and in the price and value of the products competing against it. Another challenge in developing a structured methodology is to find the right blend between simplicity and rigor. The approach must be straightforward and transparent if practitioners are to use it but sufficient rigor should exist so that users can depend on the results.

\section{DEMAND MODEL}

The S-Model attempts to strike the balance between simplicity and rigor by using a demand expression (Cook and Kolli, 1994; Donndelinger and Cook, 1995):

$n_{i}=K\left\{V_{i}-P_{i}-\frac{1}{N} \sum_{j \neq i}\left[V_{j}-P_{j}\right]\right\}$,

ebtained from a Taylor's expansion about a so-called "cartel point" where the price and value of all the competing products are the same. The parameter $N$ is the number of competitors and the summation is over the $N-1$ products competing against product $i$. The term $K$ is the negative slope of demand as a function of price. The linear expression should be valid in the vicinity of the cartel point, a reference state given by the average price and value of the competing products. The restriction of linearity limits the application of Eq. 1 to products within the same market segment. 
We see from Eq. 1 that a demand forecast requires an estimate of the values and prices of all of the products that will be competing with each other. Value benchmarking is the first step in estimating value as shown schematically in Figure 2 for the S-Model (Cook and Kolli, 1994; Donndelinger and Cook, 1995). The process involves three steps. The first step is to determine the values and value differences of the products currently competing in the market place. The second step is to consider the differences in the attributes of the products and see if the value differences found can be explained reasonably in terms of the attribute differences. If this is successful, then a forecast of the change in value of a product resulting from a proposed design change can be made by translating the attribute changes into value changes. The process of selecting the best combination of attributes for a future product using the S-Model has been termed Strategic Quality Deployment (Kolli and Cook, 1994), the box labelled SQD in Figure 2.

\subsection{DP analysis}

The values of the products currently competing in the marketplace, (noted as DP Analysis in Figure 2) are determined by solving the linear system of equations given by Eq. 1 in terms of value for known demands and prices (Donndelinger and Cook, 1995):

$$
V_{i}=\frac{N\left[n_{i}+n_{T}\right]}{K[N+1]}+P_{i},
$$

where $n_{T}$ is the total demand for the $N$ products. The difference between the values of two competing products is given by:

$$
V_{i}-V_{k}=\frac{N\left[n_{i}-n_{k}\right]}{K[N+1]}+P_{i}-P_{k}
$$

\subsection{Attribute analysis}

Three different procedures are used to estimate how the attribute differences generate value differences between the products. The VC method uses value curves, see Figure 3. 


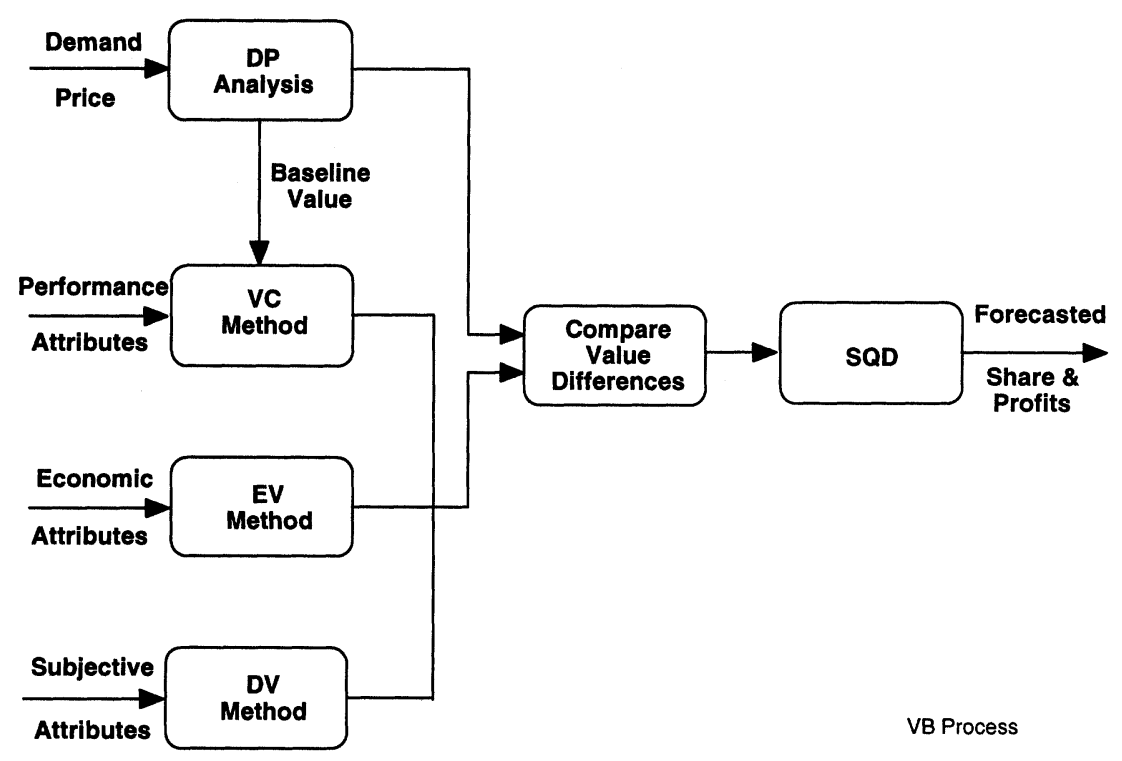

Figure 2: The S-Model value benchmarking process (Donndelinger and Cook, 1995).

A rapid method for arriving at an estimated value curve for an attribute is to use an exponentially weighted parabolic function:

$$
\mathrm{v}\left(g_{j}\right)=\left\{\frac{\left[g_{j C}-g_{j I}\right]^{2}-\left[g_{j}-g_{j I}\right]^{2}}{\left[g_{j C}-g_{j I}\right]^{2}-\left[g_{j 0}-g_{j I}\right]^{2}}\right\}^{\gamma_{j}},
$$

for value divided by the baseline value, $V_{0}$, as a function of the attribute $g_{j}$. The parameters in Eq. 3 are defined in Table 1. The value of attributes such as the fuel economy of automobiles or the operating costs of construction equipment can be estimated by straightforward economic calculations, noted as the EV method in Figure 2. Certain attributes of a product such as the style of a vehicle or the value of the name of the manufacturer of the product can be highly subjective in regard to their value. For these attributes, surveys are used in which respondents are asked their willingness to pay for a change in the attribute versus a baseline level. This is noted as the DV method in Figure 2. 


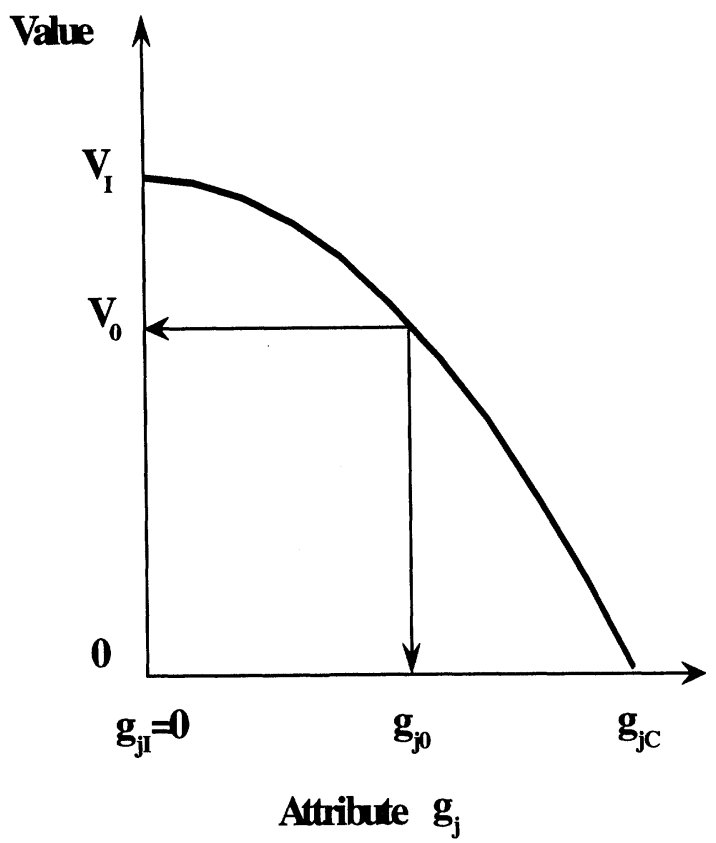

Figure 3: A schematic value curve.

The techniques can also be combined to arrive at an estimate of the value of an attribute. McConville and Cook (1995) combined the VC and DV methods to arrive at an estimate of the value of 0 to $60 \mathrm{mph}$ acceleration times for a family sedan. Donndelinger and Cook (1995) averaged the results from DV and EV methods to arrive at an estimate of the value of fuel economy. Simek and Cook (1995) used the DV method in conjunction with the VC method to arrive at the value of leg room and head room in an automobile.

\subsection{Automotive applications}

The value benchmarking process has been applied to mid-sized (Donndelinger and Cook, 1995) and compact automobiles (Schildt, 1995) in the U.S. market. The comparison between the value differences determined from the DP and attribute analyses found for mid-sized automobiles is shown in Figure 4. The vehicle brands examined have been disguised using the letters A, B, C, D, and E. The 
expression used for estimating the value of multiple attributes was the heuristic form:

$$
V_{i}(\boldsymbol{g})=V_{0} \mathrm{v}\left(g_{1}\right) \mathrm{v}\left(g_{2}\right) \mathrm{v}\left(g_{3}\right) \ldots \mathrm{v}\left(g_{j}\right)+\Delta \mathrm{V}_{\mathrm{Opt}},
$$

which was chosen because it has the property that the value of the product goes to zero (except for salvageable options, the last term in Eq. 6) when $g_{j}=g_{j C}$, where $\mathrm{v}\left(g_{\mathrm{jC}}\right)=0$.

Attributes found to have the largest impact on the value of mid-sized vehicles were the lack of an airbag for vehicle D (the other vehicles had a drivers air bag as standard equipment) and the value of the name of the manufacturer which correlated with the reliability of the vehicles reported by Consumer Reports. Schildt (1995) found for compact cars that the high customer satisfaction with the purchase and service experience at the dealership was worth $\$ 1000$ to $\$ 1500$ in value.

Table 1: Points on value curve

$\begin{array}{ll}g_{j} & \text { Attribute for factor j. } \\ g_{j 0} & \text { Baseline level for attribute j. } \\ g_{j I} & \text { Ideal level for attribute j. } \\ g_{j C} & \text { Critical level for attribute j. } \\ \gamma_{j} & \text { Weighting Factor for attribute j. }\end{array}$

\subsection{SQD waterfall of experiments}

The SQD process can be represented by a waterfall of experiments from the system to subsystem (SS) to component (C), Figure 5 (Kolli and Cook, 1994). At the system level different subsystems are evaluated versus the baseline product. The example illustrated in Figure 5 evaluates alternates for three subsystems using four experimental trials at each level. A one in a column for an alternative signifies that it is being evaluated for that trial. Trial 1 is an evaluation of the baseline product. Trial 2 evaluates a prototype which has the alternatives for SS2 and SS3 replacing their baseline counterparts, etc. 


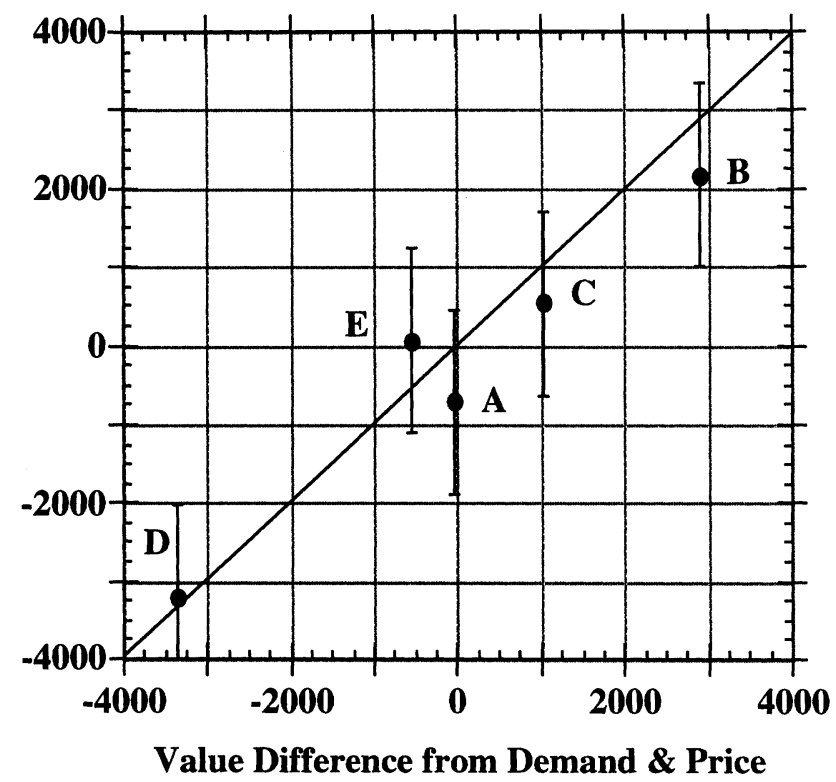

Value Diff Comp

Figure 4: Comparison of value differences for five mid-sized vehicles calculated from their attribute differences and from demand and price analysis (Donndelinger and Cook, 1995).

For each trial, the multiple system level attributes are evaluated and converted into value. The system level costs and investment for each prototype are also determined and the profitability (net cash flow) is forecast using the expression:

$$
A_{i}(\boldsymbol{g})=n_{i}(\boldsymbol{g})\left[P_{i}(\mathrm{~g})-C_{i}(\mathrm{~g})\right]-F_{i}(\mathrm{~g})-M_{i}(\mathrm{~g}),(6)
$$

where $g$ is a vector of product attributes, $n_{i}(g)$ is annual demand, $P_{i}(g)$ is the price, $C_{i}(g)$ is the variable cost, $F_{i}(g)$ is the fixed cost, and $M_{i}(g)$ is the investment. The price used for each trial $(q)$ is computed according to pricing scenario of the form:

$$
P(q)=P_{0}+\alpha_{V} \delta V(q)+\alpha_{C} \delta C(q),
$$


where $P_{0}$ is the price of the baseline product and the coefficients $\alpha_{V}$ and $\alpha_{\mathrm{C}}$ are both approximately equal to $1 / 2$ (Monroe, Silver, and Cook, 1995). The two coefficients can be changed by the system task to reflect the strategic pricing plan for the product.

System Level

\begin{tabular}{|c|c|c|c|c||c|c|c||c|}
\hline Trial & Base & \multicolumn{1}{|c|}{ SS1 } & SS2 & SS3 & \multicolumn{1}{|c|}{ Attributes } & V & C & A \\
\hline 1 & 1 & 0 & 0 & 0 & $g_{1}, g_{2}, g_{3}, \ldots$ & $V(1)$ & $C(1)$ & $A(1)$ \\
\hline 2 & 1 & 0 & 1 & 1 & $g_{1}, g_{2}, g_{3}, \ldots$ & $V(2)$ & $C(2)$ & $A(2)$ \\
\hline 3 & 1 & 1 & 1 & 0 & $g_{1}, g_{2}, g_{3}, \cdots$ & $V(3)$ & $C(3)$ & $A(3)$ \\
\hline 4 & 1 & 1 & 0 & 1 & $g_{1}, g_{2}, g_{3}, \ldots$ & $V(4)$ & $C(4)$ & $A(4)$ \\
\hline
\end{tabular}

Subsystem SS2 Level

\begin{tabular}{|c|c|c|c|c|c|c|c|c|}
\hline Trial & Base & $\mathrm{Cl}$ & $\mathrm{C} 2$ & C3 & Attributes & V & C & A \\
\hline 1 & 1 & 0 & 0 & 0 & $g_{1}, g_{2}, g_{3}, \ldots$ & $V(1)$ & $C(1)$ & $A(1)$ \\
\hline 2 & 1 & 0 & 1 & 1 & $g_{1}, g_{2}, g_{3}, \ldots$ & $V(2)$ & $C(2)$ & $A(2)$ \\
\hline 3 & 1 & 1 & 1 & 0 & $g_{1}, g_{2}, g_{3}, \ldots$ & $V(3)$ & $C(3)$ & $A(3)$ \\
\hline 4 & 1 & 1 & 0 & 1 & $g_{1}, g_{2}, g_{3}, \ldots$ & $V(4)$ & $C(4)$ & $A(4)$ \\
\hline
\end{tabular}

Component C2 Level

\begin{tabular}{|c|c|c|c|c|c|c|c|c|}
\hline Trial & Base & D1 & MI & P1 & Attributes & V & C & $\mathbf{A}$ \\
\hline 1 & 1 & 0 & 0 & 0 & $g_{1}, g_{2}, g_{3}, \ldots$ & $V(1)$ & $C(1)$ & $A(1)$ \\
\hline 2 & 1 & 0 & 1 & 1 & $g_{1}, g_{2}, g_{3}, \ldots$ & $V(2)$ & $C(2)$ & $A(2)$ \\
\hline 3 & 1 & 1 & 1 & 0 & $g_{1}, g_{2}, g_{3}, \ldots$ & $V(3)$ & $C(3)$ & $A(3)$ \\
\hline 4 & 1 & 1 & 0 & 1 & $g_{1}, g_{2}, g_{3}, \ldots$ & $V(4)$ & $C(4)$ & $A(4)$ \\
\hline
\end{tabular}

Figure 5: Waterfall of experiments. 
If, for example, system level analysis confirms that the proposed alternative for SS2 is to be used for production, then those responsible for SS2 will evaluate the possible component alternatives for this subsystem in order to meet or exceed the key requirements specified by the system level task (the internal customer of the subsystem units). A key set of component requirements is then sent to those responsible for designing and manufacturing the components. Persons within the component tasks then determine the best dimensioning, materials, and manufacturing process for meeting their internal customer's requirements at the lowest possible cost. The objective function for each trial at every level is the same, forecasted profitability. This results in the same system level attributes being evaluated for each trial at every level for conversion into value.

\section{DISCUSSION AND SUMMARY}

The waterfall of experiments shown in Figure 5 examine the impact of the alternatives considered against the multiple system level product attributes of importance to the customer. At the component level, the experiments are related to Taguchi's parameter design experiments, the difference being that a loss function is used by Taguchi Methods practitioners; whereas, forecasted profitability is used in SQD. Because Taguchi's loss function can be derived from the S-Model theory of quality, the two approaches are in harmony (Cook and DeVor, 1991). The SModel was developed to treat the full range of design issues from the system level to the component level which requires consideration of multiple attributes. Taguchi's formulation focuses on the parameter and tolerance design single attribute problem.

Product experiments are traditionally made using prototype hardware but computer simulation is a promising and growing alternative which may soon replace much of the labour and cost of prototype evaluations. It is important in the development of computer simulations of product behaviour that the engineers take the simulation "all the way to the customer" instead of ending the simulation at the point where a traditional engineering result is obtained. For example, a new suspension design for an automobile may be under consideration. The traditional engineering calculation might end at the computation of the critical wheel hop frequency and maximum possible lateral acceleration. Taking the simulation to the customer requires that the impact on the system level product attributes be computed and those translated into value and costs and ultimately into profit.

Although the S-Model is relatively new, it is already being used as a decision support tool on an experimental basis in developing new automotive and construction equipment products. As the usage increases, we expect, of course, to find areas where refinements are needed. Opportunities for improving the SQD methodology lie in developing more accurate models for 1) translating customer needs into value and 2) for converting value and cost into forecasted demand. 


\section{ACKNOWLEDGMENTS}

The author is deeply grateful to Caterpillar and Ford Motor Company for support of this research through unrestricted grants.

\section{REFERENCES}

Akao, Y. (Editor) (1990) Quality Function Deployment QFD. Productivity Press, Cambridge, Massachusetts

Chase, R.B. and Aquilano, N.J. (1995) Production Operations Management Manufacturing and Services. 7th edition, Irwin, Chicago, Illinois, 589-633.

Cook, H.E. and DeVor, R.E. (1991) On Competitive Manufacturing Enterprises I: The S-Model and the Theory of Quality. Manufacturing Review , 4(2), 96-105.

Cook, H.E. (1992) New Avenues to Total Quality Management. Manufacturing Review, 5(4), 284-292.

Cook, H.E. and Kolli, R.P. (1994) Using Value Benchmarking to Plan and Price New Products and Processes. Manufacturing Review, 7(2), 134-147.

DeVor, R.E., Chang, T., and Sutherland, J.W. (1992) Statistical Quality Design and Control. Macmillan, New York.

Donndelinger, J. and Cook, H.E. (1995) Benchmarking Product Value: Mid-sized Automobiles. Report No. UILU-ENG-95-4008.

Gitlow, H., Oppenheim, A., and Oppenheim, R. (1995) Quality Management. 2nd ed., Irwin, Burr Ridge, Illinois

Kolli, R.P. and Cook, H.E. (1994) Strategic Quality Deployment. Manufacturing Review, 7(2), 148-163.

McConville, G. and Cook, H.E. (1995) Estimating the Value Trade-off Between Automobile Acceleration Performance and Fuel Economy. Tech. Report No. UILU-ENG-95-4010.

Monroe, E.M., Silver, R.L., and Cook, H.E. (1995) Segmentation of the Market for Family Automobiles by Price and Value. Tech. Report No. UILU-ENG-954031.

Schildt, T. (1995) Value Benchmarking In The Compact Car Market. Diplomarbeit, RWTH, Aachen.

Schonberger, R.J. (1987) World Class Manufacturing Casebook, Implementing JIT and TQC. The Free Press, New York.

Simek, M.E. and Cook, H.E. (1995) A Methodology for Estimating the Value of Interior Room in Automobiles. Tech. Report No. UILU-ENG-95-4009.

Taguchi, G. and Wu, Y. (1980) Introduction to Off-line Quality Control. Central Japan Quality Association, Nagoya, Japan.

Transactions from the Fifth Symposium on Quality Function Deployment (1993) American Supplier Institute, Dearborn, Michigan. 


\section{BIOGRAPHY}

Dr. Cook's current research and academic interests are in the broad aspects of product realisation and the management of technology focusing on manufacturing competitiveness, advanced quality systems, and product management. Before joining the University, Dr. Cook was Director of Automotive Research and Technical Systems and later General Manager of Scientific Affairs at Chrysler. He helped spearhead the development of the first co-operative research partnership within the U.S. based automotive industry -- the formation of a pre-competitive research joint venture between Ford, GM and Chrysler for structural polymer based composites. He is a member of the National Academy of Engineering and a Fellow of both the American Society for Metals and the Society of Automotive Engineers. $\mathrm{He}$ is also a member of the National Materials Advisory Board. 